\title{
The importance of the World Symposium on Pulmonary Hypertension
}

\author{
Carlos Jardim,a, Daniel Waetge
}

More than 50 years ago, an epidemic of pulmonary hypertension in Austria, Germany, and Switzerland mobilized the medical community in search of answers. After evaluating the available data, the community observed a relationship between the use of an anorexic agent (aminorex) and the development of pulmonary hypertension caused by precapillary arteriopathy with plexiform lesions. $^{(1)}$

The World Health Organization organized the first World Symposium on Pulmonary Hypertension, which was held in Geneva, Switzerland, in 1973. The aim of the meeting was to aggregate and, more importantly, to share the existing knowledge on pulmonary hypertension, convening specialists from various areas-including clinicians, pathologists, and epidemiologists. The official recognition of this disease was fundamental to the organization of various research groups in search of new information to better understand and address the burden of this condition.

The recommendation for an international registry on pulmonary hypertension arose from this first world symposium. Systematic, prospective data collection could offer fundamental information to understand the natural history of this condition and allow the international community to seek or propose new interventions to improve patient survival, which was known to be short at the time. The first international registry was published only in the beginning of the 1990s and brought valuable information, including the first survival equation. ${ }^{(2)}$ Hemodynamic data, such as cardiac index, right atrial pressure, and mean pulmonary artery pressure, were shown to be relevant in terms of survival. However, after the first world symposium in 1973 and the publication of the United States registry in 1991, (2) there were few advances in the understanding and treatment of patients with pulmonary arterial hypertension. The most relevant advances in that period were studies on anticoagulation and the use of calcium channel blockers, as well as the advent and establishment of lung transplantation. However, none of those interventions represented a paradigm shift in the treatment of patients with such limited survival.

A study on the use of intravenous epoprostenol in patients with pulmonary arterial hypertension was published in 1996.(3) The results were extremely encouraging and, for the first time, showed that it is possible to reduce mortality in this patient population. At the time, research groups from various regions of the world had gathered and analyzed data not only for patients with pulmonary arterial hypertension but also for those with other forms of compromised pulmonary circulation. The group dedicated to the study and treatment of chronic thromboembolic pulmonary hypertension was noteworthy for establishing and systematizing the pulmonary artery thromboendarterectomy procedure.

The second World Symposium on Pulmonary Hypertension was held in Evian, France, in 1998. With the advent of a new drug that shifted the treatment paradigm, the critical analysis of epidemiological data, and the incorporation of surgical procedures, as well as other factors, the great contribution of this second world symposium was the proposal of a classification table for pulmonary hypertension, so that researchers and physicians from various regions of the world could organize their research and provide proper care for their patients. The classification table considered common factors that could be grouped: clinical presentation, physiopathology, pathology findings, and treatment response. Therefore, the classification system was at the time divided into five groups ${ }^{(4)}$ : pulmonary arterial hypertension; pulmonary venous hypertension; pulmonary hypertension associated with respiratory system diseases or hypoxia; pulmonary hypertension caused by thrombotic or embolic disease; and pulmonary hypertension caused by diseases that directly affect the pulmonary vessels. Each group comprised subgroups defined by specific situations or clinical presentations.

This classification proposal abandoned the then-current simplistic classification between primary and secondary pulmonary hypertension, defined by the presence or absence of known causes or risk factors. The proposal was a significant advance, because it demonstrated, although with limitations, the complexity of pulmonary hypertension. Undoubtedly the second world symposium represented the capacity of the international community to get organized and draw attention to a highly relevant health topic, especially regarding morbidity and survival.

The first study on the use of an endothelin receptor antagonist in patients with pulmonary arterial hypertension was published in $2002^{(5)}$; it was the first oral medication shown to be effective in significantly improving the distance covered in the six-minute walk test (primary outcome), in addition to having a positive impact on other disease markers. At the time, the main pathophysiological pathways of pulmonary hypertension had already been identified as those related to prostacyclins, the nitric oxide metabolism, and endothelin.

With an additional pathophysiological pathway as a target of treatment and the growing number of publications in

1. Disciplina de Pneumologia, Unidade de Circulação Pulmonar, Instituto do Coração, Hospital das Clínicas, Faculdade de Medicina, Universidade de São Paulo, São Paulo (SP) Brasil.

2. Departamento de Clínica Médica, Disciplina de Pneumologia, Faculdade de Medicina, Universidade Federal do Rio de Janeiro, Rio de Janeiro (RJ) Brasil. a. (ID) http://orcid.org/0000-0003-0425-5548 
the area, the third World Symposium on Pulmonary Hypertension was held in 2003. The classification system was once again adjusted; however, the structure of five groups was maintained, following the same precepts. In addition, the therapeutic options were updated and a new treatment algorithm was introduced. This symposium also featured clearly organized task forces focused on specific areas, especially pathology, genetics, and clinical trials.

In the following years, world symposia were held every five years. In 2008, the fourth world symposium was held in Dana Point, California. At that symposium, the clinical classification of pulmonary hypertension was adjusted and the treatment algorithm was updated, incorporating drugs, as well as designating levels of evidence and grades of recommendation for each pharmacological intervention. The use of calcium channel blockers, as well as drugs said to be specific, was established, and the implications of the response criteria $^{(6,7)}$ were incorporated. Additional epidemiological data had been collected, and one of the most important contributions of the fourth symposium was establishing the need for clinical trials that use the time to clinical worsening as the primary outcome, rather than the surrogate outcomes for severity employed in studies performed in a relatively short time period. Those data were particularly important for testing new pharmacological intervention strategies in a situation in which many patients were already medicated at the time of their inclusion in a new study.

The fifth world symposium was held in 2013, in Nice, France. The classification table was updated; new strategies and drugs were also incorporated into the treatment algorithm. From the perspective of physiopathology, the right ventricle assumed a central role, as did the task force on pathology. From the beginning of the 2000s, hemodynamics and the evaluation of the right ventricle by imaging methods began to play an important role in the diagnosis and monitoring of patients with pulmonary hypertension. ${ }^{(8,9)}$ Data from new registries for various parts of the world were also discussed, producing relevant epidemiological information in terms of age at diagnosis, survival, and risk stratification. ${ }^{(10)}$ In the following years, clinical studies based on the precepts established by the world symposium task forces were able to explore the effects of treatment strategies on aspects of morbidity, mortality, hospitalization, and quality of life. ${ }^{(11,12)}$

Lastly, a few months ago, the sixth world symposium was once again held in Nice, France. We cannot yet say what alterations and suggestions were made by the task forces, because they have not yet been published in their final form. However, we can say that pulmonary hypertension gained global relevance, ${ }^{(13,14)}$ beyond the issue of its rarer and more fatal presentation. Undoubtedly, the data will reflect the advances in the international community over the last five years.

The world symposia are both cause and consequence of the advances in pulmonary hypertension science. The meeting and the discussions, which also occur throughout the period of preparation for the event, order and illuminate the paths for this highly important area of knowledge, especially for those that face this disease; that is, patients and the community.

\section{REFERENCES}

1. Gurtner HP. Aminorex and pulmonary hypertension. A review. Cor Vasa. 1985;27(2-3):160-71.

2. D'Alonzo GE, Barst RJ, Ayres SM, Bergofsky EH, Brundage BH, Detre $\mathrm{KM}$, et al., Survival in patients with primary pulmonary hypertension. Results from a national prospective registry. Ann Intern Med. 1991;115(5):343-9. https://doi.org/10.7326/0003-4819115-5-343

3. Barst RJ, Rubin LJ, Long WA, McGoon MD, Rich S, Badesch $\mathrm{DB}$, et al., A comparison of continuous intravenous epoprostenol (prostacyclin) with conventional therapy for primary pulmonary hypertension. N Engl J Med. 1996;334(5):296-301. https://doi. org/10.1056/NEJM199602013340504

4. Simonneau G, Galiè N, Rubin LJ, Langleben D, Seeger W Domenighetti G, et al., Clinical classification of pulmonary hypertension. J Am Coll Cardiol. 2004;43(12 Suppl S):5S-12S. https:// doi.org/10.1016/j.jacc.2004.02.037

5. Rubin LJ, Badesch DB, Barst RJ, Galie N, Black CM, Keogh A, et al. Bosentan therapy for pulmonary arterial hypertension. N Engl J Med. 2002; 346(12):896-903. https://doi.org/10.1056/NEJMoa012212

6. Sitbon $O$, Humbert M, Jaïs $X$, loos V, Hamid AM, Provencher $S$, et al., Long-term response to calcium channel blockers in idiopathic pulmonary arterial hypertension. Circulation. 2005;111(23):3105-11. https://doi.org/10.1161/CIRCULATIONAHA.104.488486

7. Costa EL, Jardim C, Bogossian HB, Amato MB, Carvalho CR, Souza R. Acute vasodilator test in pulmonary arterial hypertension: evaluation of two response criteria. Vascul Pharmacol. 2005;43(3):143-7. https:// doi.org/10.1016/j.vph.2005.05.004
8. Vonk-Noordegraaf A, Souza R. Cardiac magnetic resonance imaging what can it add to our knowledge of the right ventricle in pulmonary arterial hypertension? Am J Cardiol. 2012;110(6 Suppl):25S-31S. https://doi.org/10.1016/j.amjcard.2012.06.013

9. Vonk-Noordegraaf A, Haddad F, Chin KM, Forfia PR, Kawut SM Lumens J, et al., Right heart adaptation to pulmonary arteria hypertension: physiology and pathobiology. J Am Coll Cardiol. 2013;62(25 Suppl):D22-33. https://doi.org/10.1016/j.jacc.2013.10.027

10. McGoon MD, Benza RL, Escribano-Subias $P$, Jiang $X$, Miller DP Peacock AJ, et al., Pulmonary arterial hypertension: epidemiology and registries. J Am Coll Cardiol. 2013;62(25 Suppl):D51-9. https:// doi.org/10.1016/j.jacc.2013.10.023

11. McLaughlin W, Hoeper MM, Channick RN, Chin KM, Delcroix M Gaine S, et al., Pulmonary Arterial Hypertension-Related Morbidity Is Prognostic for Mortality. J Am Coll Cardiol. 2018;71(7):752-763. https://doi.org/10.1016/j.jacc.2017.12.010

12. Channick RN, Delcroix M, Ghofrani HA, Hunsche $E$, Jansa $P$, Le Brun FO, et al., Effect of macitentan on hospitalizations: results from the SERAPHIN trial. JACC Heart Fail. 2015;3(1):1-8. https://doi org/10.1016/j.jchf.2014.07.013

13. Hoeper MM, Humbert M, Souza R, Idrees M, Kawut SM, SliwaHahnle K, et al., A global view of pulmonary hypertension. Lancet Respir Med. 2016;4(4):306-22. https://doi.org/10.1016/S22132600(15)00543-3

14. Humbert M, Khaltaev N, Bousquet J, Souza R. Pulmonary hypertension: from an orphan disease to a public health problem. Chest. 2007;132(2):365-7. https://doi.org/10.1378/chest.07-0903 